\title{
Dielectric Properties of Samarium Doped- Sodium Potassium Niobate Thin Films
}

\author{
Umar Al-Amani Azlan ${ }^{1 *}$, Nurul Azuwa Azmi², Maziati Akmal Mohd Hatta², Mohd Warikh Abdul Rashid² and Mohd \\ Asyadi Azam Mohd Abid ${ }^{2}$
}

${ }^{1}$ Faculty of Engineering Technology, Malaysia

${ }^{2}$ Faculty of Manufacturing Engineering, Malaysia

*Corresponding author: Umar Al-Amani Azlan, Faculty of Engineering Technology, Durian Tunggal, Melaka, Malaysia

Submission: 眥 November 11, 2017; Published: 眥 February 01, 2018

\begin{abstract}
This short communication revealed the importance of Samarium, Sm as a dopant in Sodium Potassium Niobate, KNN thin films. It was found that the surface roughness of about $1.583 \mathrm{~nm}$ was reduced with $\mathrm{Sm}$ doping. Furthermore, the microstructure of doping films was more uniform in term of size and shape. This also led to the improvement of dielectric properties.
\end{abstract}

Keywords: KNN, Sm, Thin films, Doping

\section{Introduction}

For the past 10 years, ferroelectric ceramics with a perovskite structure, a tungsten bronze structure, and bismuth layerstructured (BLSF) have been reported to replace the lead-based materials. Recently, more findings with better results has been reported from various perovskite-structured ferroelectrics such as barium titanate $\left(\mathrm{BaTiO}_{3}(\mathrm{BT})\right)$, bismuth titanate $\left(\left(\mathrm{Bi}_{1 / 2} \mathrm{Na}_{1 / 2}\right)\right.$ $\mathrm{TiO}_{3}$ (BNT)), bismuth sodium titanate $\left(\left(\mathrm{Bi}_{1 / 2} \mathrm{~K}_{1 / 2}\right) \mathrm{TiO}_{3}\right.$ (BKT)), potassium niobate $\left(\mathrm{KNbO}_{3}(\mathrm{KN})\right)$, sodium potassium niobate $((\mathrm{K}$, $\mathrm{Na} \mathrm{NbO}_{3}(\mathrm{KNN})$ ) [1]. Among these, $\mathrm{KNN}$ has been nominated as one of the most promising candidates to replace the wide usage of leadbased materials especially the lead zirconate titanate $\left(\mathrm{Pb}\left[\mathrm{Zr}_{\mathrm{x}} \mathrm{Ti}_{1-\mathrm{x}}\right]\right.$ $\mathrm{O}_{3}$ ). $\mathrm{KNN}$ is a combination of solid solution ferroelectric $\mathrm{KNbO}_{3}$ and anti-ferroelectric $\mathrm{NaNbO}_{3}$ that has been the most studied lead-free piezoceramics materials due to its relatively high piezoelectric constant $(416 \mathrm{pC} / \mathrm{N})$ and high Curie temperature $\left(420^{\circ} \mathrm{C}\right)[2-4]$.

The formation of KNN structure has some lacking due to oxygen vacancies and some intrinsic defects. Therefore, many researches have been done in substituting the vacancies with rare-earth and researchers still trying to find the ideal dopant to be doped into the KNN structure. Different dopants will give different effects to the materials. However, not all dopants are suitable for certain applications. In our current work, samarium (Sm) was introduced into KNN structure in order to overcome the intrinsic defects. Samarium is a member of lanthanide series with an oxidation state of +3 , atomic radii of $1.81 \AA$ and ionic radii of $0.964 \AA$, was chosen as a doping element due to its stability of perovskite phase, ionic radius and the Curie-Weiss temperature [5].

\section{Research Methodology}

The experiment was divided into precursor preparation, deposition and annealing process and followed by analysis. The precursor was started by dissolving $\mathrm{CH}_{3} \mathrm{COOK}$ and $\mathrm{CH}_{3} \mathrm{COONa}$ into 2-ME in a beaker with constant stirring at room temperature. $\mathrm{Nb}_{2}\left(\mathrm{OC}_{2} \mathrm{H}_{5}\right)_{10}$ was also prepared with a constant stirring at room temperature in another beaker containing 2-ME with the addition of acetylacetone. Later on, both of the precursors were mixed together for another constant stirring at $60^{\circ} \mathrm{C}$ for an hour. The same steps were repeated for the doping precursor, where the samarium with different concentrations was added to the beaker containing $\mathrm{CH}_{3} \mathrm{COOK}$ and $\mathrm{CH}_{3} \mathrm{COONa}$. After that, the deposition process was done by depositing the precursor onto the silicon (Si) substrate for five layers. Spin coater had been used in order to deposit the layers. One minute of pyrolysis was taking place between each of the layers. To end the deposition process, the wet films were annealed at 650 ${ }^{\circ} \mathrm{C}$ for 10 minutes by using the rapid thermal processing (RTP) furnace. The samples were ready to be characterized and analysed.

\section{Result and Discussions}

The 3D AFM surface topography micrographs for both samples are shown in Figure1. The scanned area of $1 \mathrm{~m} \times 1 \mu \mathrm{m}$ came out with roughness, Rq of $1.658 \mathrm{~nm}$ for KNN films (Figure 1a) while $1.583 \mathrm{~m}$ for Sm doping (Figure 1b). The integration of Sm as a dopant into KNN structure helps to minimize the roughness of thin films. Furthermore, the microstructure of KNN with Sm doping is more uniform in term of size and shape as compared to that of KNN. 


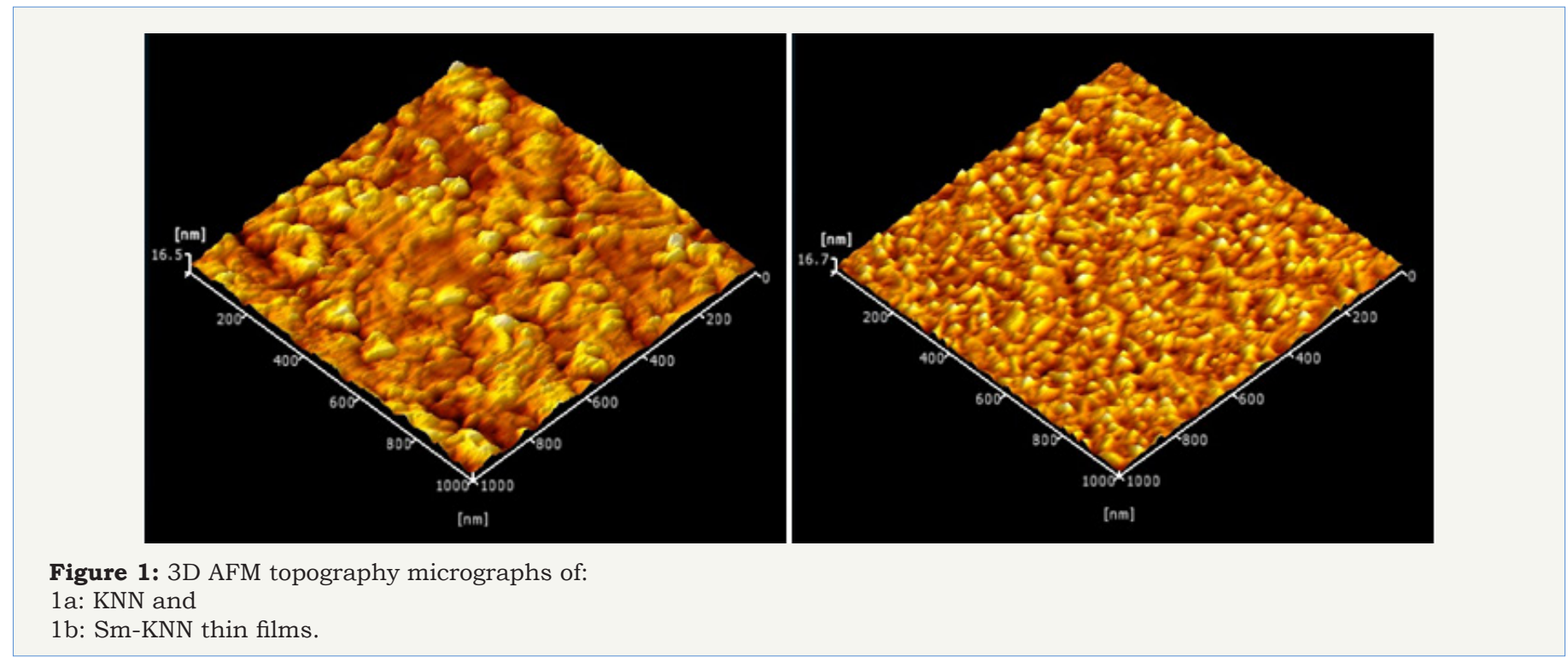

Table 1: Dielectric properties measured at $1 \mathrm{kv}$.

\begin{tabular}{|c|c|c|}
\hline & KNN & Sm-KNN \\
\hline Dielectric constant & 366 & 570 \\
\hline Dielectric loss & 0.00211 & 0.00108 \\
\hline
\end{tabular}

Table 1 shows the dielectric properties of both thin films measured at $1 \mathrm{kV}$. The incorporation of Sm into KNN shows a significant result in term of electrical properties. As seen, the dielectric constant and dielectric loss of Sm-KNN were greatly improved with $36 \%$ and $49 \%$, respectively as compared to that of KNN thin films. This improvement is in line with the uniformity of microstructure as shown clearly in Figure 1b. It is well to be said that the incorporation of Sm into KNN might be useful for fabricating this material into microelectronic devices with better dielectric properties. Further studies on the other analyses will be reported in order to have a good conclusion on this research.

\section{Conclusion}

Initial study on the comparison of KNN and Sm doped- KNN thin films were successfully carried out in this work. It was clearly seen that the improvement on surface roughness with uniform microstructure shown by the films with Sm doping, thus leading to a significant result on dielectric properties.

\section{Acknowledgement}

The author would like to thank MOHE, Universiti Teknikal Malaysia Melaka and Ministry of Higher Education under the FRGS number: FRGS/1/2014/TK04/FTK/02/F00207 for funding this project.

\section{References}

1. Takenaka T (2013) Lead-free piezoelectric ceramics. Handb Adv Ceram.

2. Rödel J, Jo W, Seifert K T P, Anton E M, Granzow T, and Damjanovic D, et al. ( 2009) Perspective on the development of lead-free piezoceramics. Journal of the American Ceramic Society 92(6): 1153-1177.

3. Saito Y, Takao H, Tani T, Nonoyama T, Takatori K, et. al ( 2004) Lead-free piezoceramics. Nature 432(7013): 84-87.

4. Shrout T R, and Zhang S J (2007) Lead-free piezoelectric ceramics: Alternatives for pzt? Journal of Electroceramics 19(1): 111-124.

5. Chon U, Kim KB, Jang HM, Yi GC (2001) Fatigue-free samariummodified bismuth titanate $\left(\mathrm{Bi}_{4} \mathrm{Sm} \mathrm{Ti}_{3} \mathrm{O}_{12}\right)$ film capacitors having large spontaneous polarizations. Applied Physics Letters 79(19): 3137-3139. 